\title{
How Digital Business Strategy Shapes Task Complexity in Datafication of Knowledge Work
}

\author{
Nico Wunderlich \\ IT University of Copenhagen, Denmark \\ nicw@itu.dk
}

\author{
Louise Harder Fischer \\ IT University of Copenhagen, Denmark \\ louf@itu.dk
}

\begin{abstract}
Traditionally, knowledge workers delivered value from complex job tasks that were determined by the amount of information they cognitively processed. In organizations practicing digital business strategies, information handling is progressively replaced by data processed for algorithmic decision support. When organizational processes are becoming increasingly data-driven, shifts in the central task component of complexity are expected. In this paper, we draw on a quantitative survey of 150 knowledge-intensive organizations in the U.S., and find that knowledge workers are perceiving increased complexity in their daily tasks, now shaped by the digital work environment. Executing a digital business strategy increases the IT dependency of business processes and emphasizes data as determinant of increased task complexity. Our research contributes to explain consequences of datafication for individual job tasks in knowledge work when organizations strategically strive to gain value from digital technologies and provides building blocks for future job design when designing for digital.
\end{abstract}

\section{Introduction}

Knowledge-intensive organizations increasingly adopt digital technologies and place datafication in the center of value creation $[1,2]$. Consequently, companies leverage digital infrastructures to benefit from the enormous amount of data from every transaction and the internet of things, before their competitors might progress accordingly [3, 4]. Datafication subsumes this transition, when qualitative behavior and tacit knowledge are increasingly replaced by quantified actions and codified data. These shifts transform the nature of knowledge work (KW) when human and digital actors begin to jointly act upon data and the organizational framework reaffirms the relevance of data [5]. While we begin to understand how these achievements result in fragmented phenomena, e.g., individualized service for customers, automated decision-making, or the rise of meta-human systems [6], we also recognize concepts on corporate strategic level that describe value creation from the evolving role of data and digital technology [4]. Still, it is yet not well understood how these conversions within knowledgeintensive organizations reflect into socio-technical changes in work-systems [7] and how knowledge workers perceive these shifts from modified characteristics of their job tasks [5].

Task complexity (TC) represents an incremental and also challenging component of job tasks, that affects human behavior and performance particularly in knowledge-intensive organizations in pursuit of efficient problem solving [8,9]. While $\mathrm{KW}$ persists of non-routine and cognitive tasks that are in general multi-faceted and complex [10], factors that traditionally shape TC undergo conversions. From a theoretical perspective, TC increases with the number of executed activities, with the amount of processed information, and when the interdependence between information and activities progresses [11]. In the setting of organizations pursuing a digital business strategy (DBS), knowledge workers encounter the transforming issue that data - produced by and in the digital ecosystems - pushes traditional human information seeking, cognition, and reasoning to the fringes [12]. In turn, decision-making as a cognitive knowledge job task becomes increasingly supported and partly overtaken by algorithms and artificial intelligence. While the datafication of KW as phenomenon describes this shift from intuitive and qualitative decision-making towards being rather quantitative and codified $[5,12,13]$, it is still unclear how the superior organizational framing of a DBS impacts the complexity of individual knowledge tasks. To better understand the effects on task characteristics through favoring data in $\mathrm{KW}$, we pose the research question: How does a digital business strategy shape the complexity of job tasks in $K W$ ?

In this paper we zoom in on individual TC, as the concept is seen as an important component that 
influences performance, behavior, and value creation at the individual level of knowledge workers [9-11]. Hence, it is exposed to reframing when designing for digital. We rely on knowledge workers' perceptions to assess how they comprehend shifts in their task characteristics along datafication of KW. To bridge this perception between individual job tasks and the enterprise level of a DBS, we refer to and refine the construct of IT dependency [14], that expresses the reliance of a company's business processes on well-functioning and reliable IT. The remainder of the paper is organized as follows: first, the theoretical background of the investigated concepts is further highlighted. After developing the underpinning hypotheses, we test the succeeding research model by means of structural equation modeling based on the results of an online survey among 150 individual knowledge professionals in knowledge-intensive organizations. Finally, we discuss the results and limitations and give advice for future research when relating our results to the digital organization as an overarching sociotechnical phenomenon.

\section{Literature Background}

From a theoretical perspective, we refer to contingency approaches of organizational design, that prescribe how a company's structure and systems follow the pursued business strategy as well as the employed technology $[15,16]$. In this section we review literature on the following three concepts: DBS (enterprise level), IT dependency (organizing level), and TC (individual level) to prepare an understanding of their interdependencies in shaping data job tasks in $\mathrm{KW}$.

\subsection{Digital Business Strategy at Enterprise Level}

A DBS defines an organization's guideline in how to gain business value from digital resources [4]. As to business strategies in general, a DBS signals to the company, including its staff, how to achieve marketoriented goals [16]. Companies can expect positive effects if a large proportion of the workforce is reached through this internal, resource configuring function, especially when involving colleagues fulfilling tasks with higher strategic relevance, such as managers and knowledge workers [17]. Especially in digital work environments, employees' awareness of their company's goals gains increased importance for coordinated actions due to intense horizontal and decentralized collaboration and remote work $[18,19]$. The fusion of the formerly separate concepts of a business and a separate IT strategy manifests the incremental value IT is granted for the entire organization when the functional strategy is promoted into a corporate strategy. A DBS outlines the organization's plan for digital value creation along the four themes of scope, scale, speed, and source [4]. The concept favors a crossfunctional scope of overcoming functional silos, embracing the entire organization, and exploiting the richness of multi-sided partnerships reaching out in the organization's digital ecosystem [20]. A scalable IT infrastructure enables to leverage network effects and digital platforms of increased connectivity. This allows for accelerated decision making and for higher frequency of product launches and updates [18]. Speeding up and learning from those digital supply chains underlines the abundance of data as main source of value creation when executing a DBS $[1,6]$.

\subsection{IT Dependency at Organizing Level}

Business dependence on IT is one framing of an organization's IT focus [14]. Competing in digital environments requires multifold IT dependent activities of embedding the organization in the surrounding digital infrastructure, such as developing and maintaining alliances and partnerships or learning from constantly accruing (big) data $[3,4]$. The corresponding IT dependency indicates how the operation of the organization's core activities is determined by mission-critical information systems (IS). Organizations with a higher focus on IT outperform less IT-driven organizations, since the previous utilize IT to a greater extent for achieving competitive advantage, such as closer linking with suppliers and customers or raising barriers for new markets entries [21]. Traditionally, a higher focus on IT for core activities leads to higher investments in IT, especially for those that drive business objectives with impact on organizational performance [22]. While the continuation of IT dependent business processes relies on stable and efficient IT operations, the IT department is still seen as the main beneficiary of those IT investments [23, 24]. This line of thinking is determined to measure the intensity of IT investments for a long time by the budget spent for the IT unit in proportion to the organization's overall revenue or costs $[25,26]$. Recently, the strategic postulation of value creation from digital business initiated a discussion of fading boundaries of IT departments in favor of a pervasive, progressively decentralized function $[18,24]$. This decentralization challenges the established measurement of IT dependency if only considering the budget of the IT department, when dynamic interaction with the ecosystem as well as the fusion of business and IT for value creation emphasize case focused, process-specific IT decisions [1, 27]. Organizations pursuing such decentralized data-driven 
decision-making perform more productive and profitable than competitors, even after taking efforts of traditional IT investments into account [28]. Executing a DBS thus supposes to imply higher levels of IT dependency on the organizing level and to capture IT dependency in digital environments on a broaders [4, 23].

\subsection{Task Complexity at Individual Level}

Job tasks are a central element in organizations' pursuit of goals and value creation. An important characteristic of tasks is its degree of complexity [11,29]. Tasks contain three essential components; products, (required) acts, and information cues. These constructs are the building blocks for the definition of determining TC. An increase in the task component of complexity is attributed to the occurrence of more information cues to be processed, more acts to be executed, or of increased interdependence between the cues and acts [11]. TC and its importance in organizational value creation have been researched in three different streams of literature: 1) information-processing and decision-making, 2) task and job design, and 3) goalsetting [30]. In this study, we draw on the first stream to elaborate the RQ, as TC is found as a being key determinant when individuals select decision process strategies. Illustratively, when faced with a low-complexity task, decision makers employ a compensatory decision process strategy, in which one weighs the positive and negative attributes of the considered alternatives, which allows for positive attributes to compensate for the negative ones. In a high-complexity task, decision makers follow a non-compensatory process and focus on selective information, whereby this non-compensatory decision-making strategy eliminates alternatives that do not meet a particular criterion [31]. The overarching task in $\mathrm{KW}$ is dealing with complex problems and to take decisions in non-routine situations $[32,33]$. By definition, this require cognitive abilities, that are seen as an inherent element of KW [34]. KW as such is multi-faceted [10, 11] and how to manage complexity in KW has often been a focus in the domain of Knowledge Management [9, 34]. As an example, managing complexity in $\mathrm{KW}$ relates to the degree of individual autonomy vs. company control, and free vs. provisional access to information in relation to routine or non-routine tasks [9], as the amount of information cues and related acts and their interdependencies determines complexity [11]. When problem solving and decision making are driven by datafication, the complexity increases in these particular settings, because more interdependent acts occur through replacing individual information seeking with cues from data [35].

\section{Research Model and Operationalization}

\subsection{Hypotheses and Research Model}

According to the presented background literature, we support our theoretical framing of contingency in organizational design with considerations around organizational levels of strategic information systems [36] to theoretically ground the assumed interrelation between a DBS, IT dependency of business processes, and individual TC, partially determined by data. As presented in our research model (figure 1), we propose to model the shaping effects of a DBS on KW via three organizational levels: the enterprise strategy level represented by the DBS; which then reflects to the organizing level of IT dependency and the IT supply for business processes; when finally framing the complexity of individual job tasks at the level of resource exploitation by (data-driven) problem-solving. In terms of our suggested research model, we hypothesize in both segmentation and transmittal approaches [37]. For hypotheses 1 and 2, we follow segmental hypothesizing of stepwise discussion of the individual paths. Hypothesis 3 considers the mediation as part of the postulation and thereby corresponds to a transmittal formulation of hypotheses.

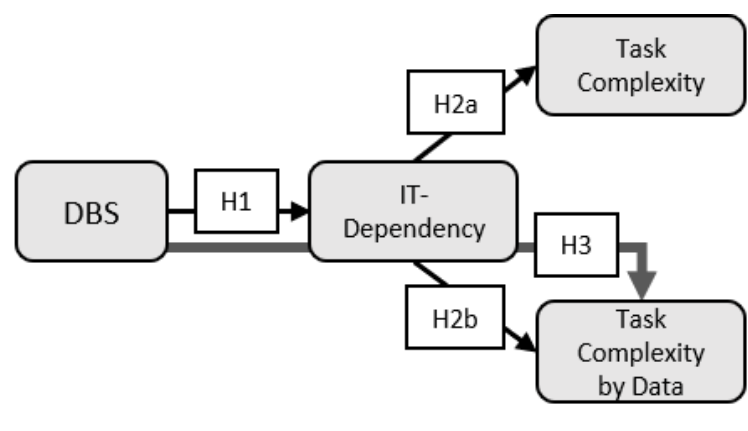

Enterprise level Organizing level Resource level

Figure 1. Research Model

A DBS pursues business value creation from data and digital resources [4]. The incremental inseparability of business and IT in digital business supposes a high IT dependency of a company's business processes when following a DBS. If organizations become more dependent on IT in their daily transactions, IT becomes critical for competitive success and survival of the firm [14]. Higher levels of executed DBS on enterprise level should result in stronger integration and supply of IT on the organizing level to accomplish the IT-intensive business processes. Thus, we propose our first hypothesis: 
H1: Executing a DBS increases the IT dependency of the organization's business processes.

Complex job tasks in KW are highly interdependent with other job tasks, outcomes of cooperating knowledge workers, and other departments $[9,11]$. In digitized companies, data becomes a relevant resource to solve problems and build decisions in appropriate time to apply with the dynamic digital market environment $[4,20]$. When the interdependent decisions of knowledge workers agglomerate in compounded decision-making processes, we can assume that these cognitive decisions are IT dependent to some extent when carried out [28, 32] (H2a). Since the amount of data and information determines TC in KW $[9,11]$, we propose that higher IT dependency of decision processes at the organizing level develops complexed job tasks when relying on data $(H 2 b)$. Thus, hypotheses 2 reads:

H2: Higher IT dependency of business processes increases the cognitive TC in $\mathrm{KW}(\mathrm{H} 2 a)$ as well as TC by data $(H 2 b)$.

Executing a DBS implies both extensive use and dependence on IT, since digital business requires the implementation and adoption of IT as incremental resource and input factor. While decisions in digital organizations base gradually on data and decisions themselves form a crucial part of KW [32, 35], we assume that such data-driven decision-making increases TC. Compared to cognitive TC, we expect that the dependency on IT infrastructure, digital platforms, and the pressure for accelerated decision-making leads to higher TC when driven by data. Following these assumptions, we pose:

H3: The execution of a DBS increases TC by data more than cognitive TC. (Transmittal hypothesis mediated by IT dependency)

\subsection{Operationalization of Constructs}

All relevant measures were adopted from extant research in the field of IS or motivated from the discussion in the literature review section (table 1).

Digital Business Strategy (DBS): The DBS is captured in representation of the four themes scope, scale, speed, and source as originally described by Bharadwaj et al. [4]. The items itself are adopted from a quantitative study on organizational strategy building at leadership level in knowledge intensive industries [38]. By means of an exploratory factor analysis, the featured scale development procedure extracted five items that are strictly in line with the initial theoretical conceptualization of a DBS [4]: Factor scope (DBS4) asks about reaching across organizational silos and into the digital ecosystem; the scalability of a DBS describes benefits from an abundance of data, information, and knowledge (DBS7); factor three captures how the speed of learning improves decision making (DBS 10); and the source of value creation when following a DBS measures the contribution of catalyzed, multisided business models and of leveraging the organization's digital architecture (DBS15, DBS17).

IT Dependency (ITD): This construct describes the reliance of an organization's business processes on IT, required to ensure its stability and continuity as well as quality and execution. Particularly with the context of digital business, IT becomes an inevitable core element of value creation $[4,18]$. In distinction to the traditional measures of IT intensity from the IT unit's budget, our conceptualization refers to a more comprehensive approach to measure IT dependency across the enterprise along more decentralized IT decisions for business processes [4]. Consequently, we adapt a rare instrument of a verbal expression of IT intensity from a study on IT capabilities [39] (ITD1,2,3) and complement it with two self-developed items that especially articulate the inevitability and risk of breakdown damage of IT for digital business (ITD 4+5). Theoretical backing for those two items is provided from a study that examines business dependence on IT as one facet of an organization's IT focus [14]. This study explicitly assesses the interactions of IT dependency with environmental factors such as the industry's information intensity, which we can recover in the discussion of the context of a DBS under the uncertainty and information abundance of the ever-developing digital infrastructure [3, 4].

Task Complexity (TC): The instruments for this construct adopt a measurement from studies of information sources and task-technology fit in the field of IS and capture its perception by individual workers $[29,40]$. We ask into the acts of dealing with complex problem solving as this is identified as the overarching task of knowledge workers [2]. For TC we present four items as derived initially for cognitive, non-IT influenced tasks, since the technology aspects in the original study were modeled in a separate construct [29]. The task characteristics of complexity are thus described through capturing the equivocality and interdependence of job tasks from a cognitive perspective when dealing with business problems (TC1-4). The items of TC represent the amount of interconnectedness with other work groups (TC3), as supposed for horizontal coordination in digital work $[28,35]$.

Task Complexity by Data (TCD): To examine the shifts of TC determined by data in the course of a DBS and data-driven decision-making, we follow the added items of Zimmer et al. [40] that emphasize the role of data and adapt those slightly (TCD1-3). As driven by digital value creation, these items allow to capture effects of how data replaces and improves 
information cues and alters the moderating effect from IT dependency. Referring to [5, 9-11], the items measure how TC becomes induced by data and raises timeconsuming preparations caused by decision-making strategies (TCD1-3).

\begin{tabular}{|c|}
\hline Digital Business Strategy $[4,38]$ \\
\hline $\begin{array}{l}\text { DBS4: How well does your company exploit the } \\
\text { extended business ecosystem? }\end{array}$ \\
\hline $\begin{array}{l}\text { DBS7: How well does your company take ad- } \\
\text { vantage of data, information, and knowledge abun- } \\
\text { dance? }\end{array}$ \\
\hline $\begin{array}{l}\text { DBS10: How effective is your company in speed- } \\
\text { ing up learning for improving strategic and opera- } \\
\text { tional decision making? }\end{array}$ \\
\hline $\begin{array}{l}\text { DBS15: How effective is your company in leverag- } \\
\text { ing value from multisided business models? }\end{array}$ \\
\hline $\begin{array}{l}\text { DBS17: How effective is your company in appro- } \\
\text { priating value through the control of the firm's digi- } \\
\text { tal architecture? }\end{array}$ \\
\hline $\begin{array}{l}\text { IT Dependency (ITD 1-3: [39]; ITD4+5: [14] and } \\
\text { self-developed) }\end{array}$ \\
\hline ITD1: IT is used extensively by our competitors. \\
\hline $\begin{array}{l}\text { ITD2: IT is used extensively by our suppliers and } \\
\text { business partners. }\end{array}$ \\
\hline $\begin{array}{l}\text { ITD3: IT is a critical means to interact with custom- } \\
\text { ers in this industry. }\end{array}$ \\
\hline ITD4: Without IT, our daily business cannot be run. \\
\hline ITD5: Our daily business completely relies on IT. \\
\hline Task Complexity $[10,11,29,40]$ \\
\hline $\begin{array}{l}\text { TC1: I frequently deal with unstructured business } \\
\text { problems }[9,11]\end{array}$ \\
\hline $\begin{array}{l}\text { TC2: I frequently deal with ad hoc, nonroutine } \\
\text { business problems }[9,10]\end{array}$ \\
\hline $\begin{array}{l}\text { TC3: The business problems I deal with frequently } \\
\text { involve more than one organizational group [11] }\end{array}$ \\
\hline $\begin{array}{l}\text { TC4: The business problems I work on involve an- } \\
\text { swering questions that have never been asked in } \\
\text { that way before. [9] }\end{array}$ \\
\hline Task Complexity by Data $[5,9,40]$ \\
\hline $\begin{array}{l}\text { TCD1: In my job, there is a great deal of variety in } \\
\text { the problems, issues, or questions for which I need } \\
\text { data }[10,11]\end{array}$ \\
\hline $\begin{array}{l}\text { TCD 2: In my work, I frequently have to think } \\
\text { about business problems and the associated data in } \\
\text { new ways }[11,32]\end{array}$ \\
\hline $\begin{array}{l}\text { TCD 3: It is necessary to spend time thinking about } \\
\text { how best to address a business problem before I } \\
\text { begin an analysis }[9,35]\end{array}$ \\
\hline $\begin{array}{l}\text { All constructs measured on 5-point Likert scale: } \\
1=\text { not applicable at all, } 5=\text { completely applicable }\end{array}$ \\
\hline
\end{tabular}

Table 1. Operationalization of Measurements

\section{Data Collection and Research Analysis}

\subsection{Survey Sample and Data Preparation}

To study the phenomenon of datafication of $\mathrm{KW}$ and consequences for reframing TC characteristics, we follow established approaches in occupational psychology and investigate our hypotheses from the perspective of individual knowledge workers. Aiming at first explanations of the rather novel phenomenon of datafication at an early stage, we follow a cross-sectional research design to reveal covariance between variables of employee perceptions, as recommended for studying job characteristics such as task complexity [41]. Consequently, we collect our data from perceptions of respondents employed in those occupations in knowledge intensive industries and knowledge intensive departments.

To test our hypotheses empirically, we conducted an online survey on our behalf and invited 4,000 members of an online panel between August 2019 and March 2020. Maintained by a large international market research institute, the online business panel contains professionals from a wide range of industries, organizational levels, and vocations. To assess the perceptions of knowledge workers on datafication, we surveyed organizations in knowledge-intensive industries as classified by the OECD [42], referring to these categorizations as recently applied in the field of IS [e.g. 19]. Knowledge-intensive organizations take higher investments in IT, what increases the likelihood that knowledge workers in the addressed corporations are facing business processes of high IT dependency $[14,42]$. Table 2 displays how these categorizations are represented in our sample. With 2,400 initial accesses to the online survey, we continuously screened out for organizational qualities such as knowledge intensive sectors, firm sizes of minimum 50 employees, or IT unit size as well as for individual characteristics of job position and affiliation with a knowledge intensive department (table 3). After applying several online and a posteriori checks and procedures to reassure response quality, we analyze a sample of 150 respondents in this study. The average organization in the sample exhibits a firm size of 64,100 employees and was established in 1932. With 16 companies founded in or after 1998, our sample contains a smaller degree of "digital-born" organizations [43]. While interpreting our results, we consider the sample characteristics to allow for an understanding of incumbent organizations.

The average knowledge worker in our sample is 50 years old and in $59 \%$ of the cases female. With an average organizational tenure of 14.4 years, the 
respondents indicate an IT experience of 10.6 years on average. Our respondents are equally distributed in three groups of education, either high school and associate level $(n=48)$, bachelor's degree $(n=57)$, or master's degree and $\mathrm{PhD}(\mathrm{n}=45)$. Half of the knowledge workers fulfill a position as academically trained professionals, plus around $10 \%$ holding a managerial position, which complies with the tracked levels of education. Based on 52 predefined types of departments as offered in the questionnaire, table 3 reports the respondents' organizational unit with more than three entries, thereby specifying $75 \%$ of the sample. In sum, the sample provides a valid basis to analyze challenges of knowledge workers in predominantly incumbent knowledge-intensive organizations in the U.S.

\begin{tabular}{|l|l|}
\hline Knowledge Intensive Industries \\
\hline Aerospace, Automotive, Defense & 7 \\
\hline Banking, Finance, Insurance & 26 \\
\hline Chemicals, Pharmaceuticals & 7 \\
\hline Consulting, Market Research, Advertising & 4 \\
\hline Education, Training & 30 \\
\hline Healthcare, Medical & 30 \\
\hline Industrial Manufacturing & 20 \\
\hline IT & 17 \\
\hline Legal Services & 9 \\
\hline $\mathbf{N}$ & $\mathbf{1 5 0}$ \\
\hline
\end{tabular}

Table 2. Industry Characteristics

\subsection{Measurement Model Validation}

For testing the proposed hypotheses, we computed the data within a structural equation model (SEM) by means of the software SmartPLS v.3.3.3 [44]. As displayed in figure 2 , the test results confirm the segmentational hypotheses $(\mathrm{H} 1, \mathrm{H} 2 \mathrm{a}+\mathrm{b})$ at the highest significance below $\mathrm{p}<0.001$. The transmittal hypothesis $\mathrm{H} 3$ can be stated additionally by the combined examination of the significant segmental path coefficients and the results of the mediation analysis. The conducted component-based SEM approach requires few assumptions regarding sample size and distribution [45]. These affordances as well as testing the proposed relationships based on several types of data and theoretical models within the complementary bootstrapping procedure emphasize its applicability for explorative analyses and earlier stages of theory testing that require in-depth analysis [46, 47]. In general, the PLS method is oriented towards prediction by estimating latent variables as exact linear combinations of observed measures [47]. We additionally calculated the model assessment employing a components-based approach with a 500 sample based bootstrapping technique $[46,47]$.

\begin{tabular}{|l|l|}
\hline \multicolumn{2}{|l|}{ Job Position } \\
\hline Generally trained office worker & 28 \\
\hline $\begin{array}{l}\text { Vocationally trained IT-specialist, techni- } \\
\text { cian, craftsperson, or equivalent }\end{array}$ & 16 \\
\hline $\begin{array}{l}\text { Academically trained professional or equiv- } \\
\text { alent (but not a manager of people) }\end{array}$ & 75 \\
\hline $\begin{array}{l}\text { Manager of one or more subordinates (non- } \\
\text { managers) }\end{array}$ & 17 \\
\hline Others, incl. freelancer, part-time workers & 14 \\
\hline Departments (n>3) & 9 \\
\hline Accounting, Finance & 28 \\
\hline Administration & 7 \\
\hline Customer Service & 4 \\
\hline Engineering and Design & 4 \\
\hline Human Resources & 25 \\
\hline IT & 4 \\
\hline Legal & 8 \\
\hline Medical, Health & 5 \\
\hline Quality Assurance and Control & 5 \\
\hline Research \& Development & 13 \\
\hline Training \& Education & 38 \\
\hline Others (n<4) &
\end{tabular}

Table 3. Characteristics of Knowledge Workers

Based on the described data set of 150 respondents, we pursue an explanatory contribution from the dependent variables between 0.100 and 0.169 at moderate levels of $\mathrm{R}^{2}$ (table 4). Several tests of the four reflective measurement instruments for reliability, convergent validity, and discriminant validity (table 4) reveal fully acceptable values above the required thresholds without exception. For reliability, the assessed average variance extracted (AVE) and composite reliability (CR) are found clearly beyond 0.5 (AVE) and 0.7 (CR) [47]. Cronbach's alpha clearly exceeds the even more sophisticated minimum value of 0.8 [46]. Evaluating the entire model fit, the Standardized Root Mean Square Residual (SRMR) of 0.064 performs for the average residual correlations as desired below the common threshold of 0.08 [46].

For the two dependent variables of TC, all items were posed in the questionnaire within one question block, bearing the risk of order bias [48]. Still, the order of the questions was automatically randomized per respondent, applying an implemented feature of the online survey tool. From the results of the discriminative analyses (table 4) we can draw that the homogeneity within the two separated constructs of TC withstands the risk of order bias, since we find the Fornell Larker criterium [49] fulfilled, in terms of the value in the diagonal to be the highest per row and column. We deliberately refrain from a conceptualization in shape of a second order construct since we are explicitly interested in understanding the difference between the 


\begin{tabular}{|c|c|c|c|c|c|c|c|c|}
\hline Construct & AVE & CR & Alpha & $\mathbf{R}^{2}$ & $(1)$ & (2) & (3) & (4) \\
\hline Digital Business Strategy (1) & 0.766 & 0.942 & 0.925 & - & $\mathbf{0 . 8 7 5}$ & & & \\
\hline IT Dependency (2) & 0.733 & 0.892 & 0.866 & 0.133 & 0.364 & $\mathbf{0 . 8 0 6}$ & & \\
\hline Task Complexity (3) & 0.650 & 0.875 & 0.825 & 0.100 & 0.156 & 0.314 & $\mathbf{0 . 8 0 3}$ & \\
\hline Task Complexity by Data (4) & 0.644 & 0.887 & 0.821 & 0.169 & 0.191 & 0.409 & 0.758 & $\mathbf{0 . 8 5 6}$ \\
\hline AVE = Average Variance Extracted; CR = Composite Reliability; Alpha = Cronbach's alpha; \\
Square root of AVE shown on diagonal, with bolded correlations significant at p $<0.05$ (two-tailed) \\
\hline
\end{tabular}

Table 4. Reliability, Validity, and Correlations

segregated path coefficients. Besides, implementing a second order construct requires a higher sample size due to the double use of the indicators, which might interfere with the validity of the computed structural relations [46]. In addition, we were interested if the measured difference between the path coefficients of the two dependent variables of TC $(0.313,0.412)$ is significant to be interpreted. Therefore, we rely on the t-test for the equality of regression coefficients [50]. Applying the computed values from SmartPLS [44] (S.D.: 0.104 and 0.098), we calculate a highly significant Zet-value of $Z=-8,49$ by transforming the standard deviation into the standard error (S.E. $=$ S.D. $/ V$, $\mathrm{n}=150$ ). Thus, we can reject the null hypothesis that both path coefficients are equal, meaning that the two regarded path coefficients significantly differ.

We conducted a mediation analysis of the two nonhypothesized associations connecting DBS with the two TC constructs directly, in accordance with the prescribed procedures based on distribution-independent bootstrapping results [46, 51]. Both mentioned path coefficients are around zero and therefore far from a relevant significance level (path coefficients 0.035 and 0.043). This test result certifies our proposed hypotheses to cover all relevant of the possible connections in the structural model. Above all, it underlines the compelling necessity to discuss IT dependency as full mediator when assessing the reflection of a DBS into the complexity of job tasks (hypothesis 3 ).

As controls, we checked for the organizational variables firm size, firm age, and industry as well as respondents' age and gender for all dependent variables (IT dependency, both TC constructs). We found two significant effects on IT dependency, namely of firm age (year of foundation) and respondent age. For the latter, the average age of 50 among the respondents influences the perception of IT dependency partially $(0.138$ at $5 \%$ level). Still, the effect of the former, year of foundation, influences this singular construct on higher degree (0.159), meaning that the younger an organization, the higher its IT dependency. This finding for the control of firm age justifies the eligibility of our measures for investigating the research question, since the identified control effect states the plausible assumption of an increase of IT dependency for younger organizations such as digital-born companies [43].

\section{Discussion}

\subsection{Results}

Following our tested research model, we were interested in assessing shifts in framing TC in datafied knowledge work. Considering causal and contingent relations from literature, we assumed that information cues are replaced with an abundance of datapoints when job tasks are enriched by data. This shift was supposed to increase task complexity due to intensified interconnectedness between more IT dependent processes and to decrease cognitive, analogue-driven autonomous acts. We posed three hypotheses to examine how knowledge workers perceive the influence from the organizational frame of a DBS on their daily tasks. All three hypotheses could be verified by statistical testing and validation within an SEM. The overall result provides a more defined picture of increased TC

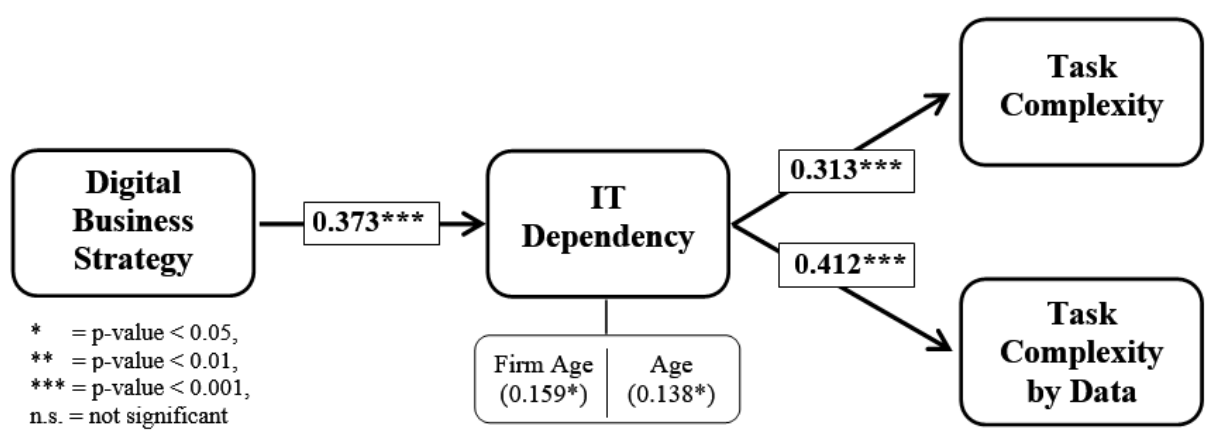

Figure 3. Resulting Structural Model 
in KW by data in the 150 surveyed knowledge-intensive organizations.

For H1, we state that executing a DBS increases the IT dependency of business processes. The firmwide guideline that signals how to generate business value from digital resources results in higher reliance on IT. The successful execution of business processes becomes progressively dependent on IT in organizations that follow a DBS. This finding confirms considerations on digital value creation by DBS $[4,18]$ supporting that digital business is only possible if organizational IT works fine. The factor loadings in the SEM especially weight the two newly developed items against the three items as adopted from [39], which emphasizes our considerations to measure IT dependency broader than traditionally focused on the IT department and the applicable IT intensity only. Secondly, $\mathrm{H} 2$ confirms the positive influence of IT dependency on TC in datafied KW. From the perceptions of the surveyed knowledge workers, a DBS translates into an increased IT dependency of business processes (H1), which they recognize as shaping their job tasks. The confirmation of $\mathrm{H} 2$ demonstrates how the utilization of IT for competitive advantage, as expressed in IT dependency, drives TC by increasing linkages among knowledge workers [14]. The particular usage of data in problem-solving as incremental element in $\mathrm{KW}$ raises TC as induced by IT dependent business processes.

Our third hypothesis was shaped as a transmittal postulation in which we posed that the execution of a DBS increases the TC by data more than cognitive TC. We find TC now progressively shaped by data. Lesser the individual knowledge workers themselves than the implementation of a DBS determines the relevant job characteristic of complexity by favoring data instead of cognitive processed information. This challenges the established assumption of high degrees of job autonomy in KW [17]. The shift towards data-driven complexity is important to address, as it fundamentally alters both the changing nature of $\mathrm{KW}$ from analogue towards digitally framed processes, and, more specifically, how the cognitive contribution of knowledge workers in the digital organization becomes predominated by logics of the infrastructure, algorithms, and predefined data-points.

\subsection{Conclusion}

This study finds evidence for the shaping influence of a DBS on TC in knowledge-intensive industries as determined by data. Studying individual knowledge workers in 150 U.S. organizations that pursue a DBS reveals detailed results about the organizational context of datafication of KW. While automated data- points extend the selective information focus in decision making, knowledge professionals perceive an increase in the complexity of their daily tasks.

In this study, we assess the three concepts DBS (enterprise level), IT dependency (organizing level), and TC (individual level) for the first time in a singular research model. We create a deeper understanding of how their interplay shapes KW in the era of datafication. Our results imply that knowledge workers in a data-driven and IT-dependent organization perceive an ultimate increase in TC. Whereas KW embraced traditionally cognitive, autonomous, and qualitative acts, data is now supposed to scrutinize these assumptions by transforming conventional decision making and replacing information [2, 33]. However, as our analysis discloses, IT dependency and data produced by digital infrastructure drive a convergence of these acts, cues, and outcomes into more controlled, codified, and planned service and processes, which are highly dependent on IT [3, 4]. This data penetration as implied by a DBS - raises TC and affects the autonomous element how individual workers decide what activities to choose and with which solutions to move forward [17]. Our findings support discussions on the automation of routine tasks, where the more complex tasks are left to the human knowledge worker [5, 6].

We measured the concept of DBS strictly in line with its original, theoretically developed postulation $[4,38]$ which allows us to understand how this organizational framework determines the job tasks of knowledge workers. While we know that employees become more involved with higher levels of implemented DBS [18, 19], our sample demonstrates how the highly qualified group of knowledge workers perceives such shifts towards digital value creation from their perspective. $\mathrm{KW}$ requires reconciliation with business strategy due to its high degrees of individual work autonomy [17]. In our cross-sectional measurement [41], knowledge workers associate being guided by a digital business strategy with increased complexity in their workplace under the changing conditions of datafication.

Following from our theoretical perspective of contingency in organizational design, we validate that IT dependency mediates in coordinating and implementing the affordances of the DBS on the organizing level of business processes $[15,16,36]$. On a philosophical level it remains an open question, if digital, datadriven organizations impact knowledge workers in the same profound way that manufacturing workers were affected through automation [7]. Yet, a dynamized business environment and the increased inseparability of business and IT for digital value creation demand a focus on decentralized, situational IT decisions [52, 53]. Our construct refinement of measuring IT 
dependency broadens its perspective beyond the limited consideration of the IT department's budget in favor of organization-wide business processes [14, 27]. Such dependency on IT increasingly emphasizes interdependency among actors and departments for digital value creation, promoting cross-functional work groups to combine several knowledge sources within and beyond organizational boundaries [1, 28, 54].

As to any research, our study is exposed to certain limitations. At first, the number and selection of knowledge intensive organizations delivers a sample of balanced characteristics, though higher sample sizes and a broader geographical reach could increase the representation of the population and reveal further insights on digital-born companies. Second, the chosen method of investigating the knowledge workers' perspectives implies the occurrence of common method bias in our self-reported data, as partially found for the control of age in our sample [48]. Future investigations could validate the findings with additional data sources, such as archival firm data. As such, our research opens further paths for longitudinal investigation [41] as the complexity of data-driven work tasks is expected to continue to rise. Future research might focus on implications for sociotechnical changes in work-systems by assessing shifts in task components and complexity and how datafication impacts behaviors, performance, and value creation $[7,11]$.

\section{References}

[1] Snow, C.C., Ø.D. Fjeldstad, and A.M. Langer, "Designing the digital organization", Journal of Organization Design, 6(7), 2017.

[2] Newell, S., "Managing Knowledge and Managing Knowledge Work: What we know and what the Future holds", Journal of Information Technology, 30, 2015, pp. 117.

[3] Tilson, D., K. Lyytinen, and C. Sørensen, "Research Commentary -Digital Infrastructures: The Missing IS Research Agenda", Information Systems Research, 21(4), 2010, pp. 748-759.

[4] Bharadwaj, A.S., O.A. El Sawy, P.A. Pavlou, and N.V. Venkatraman, "Digital business strategy: toward a next generation of insights", MIS Quarterly, 37(2), 2013, pp. 471482.

[5] Fischer, L.H. and N. Wunderlich, "Datafication of Knowledge Work: A Framework and Research Agenda", 54th Hawaii International Conference on System Sciences (HICSS 2021), 2021.

[6] Lyytinen, K., J.V. Nickerson, and J.L. King, "Metahuman systems $=$ humans + machines that learn", Journal of Information Technology, 2020.

[7] Fischer, L.H., "Theorizing Universal Sociotechnical Mechanisms", Proceedings of the 6th International
Workshop on Socio-Technical Perspective in IS Development (STPIS 2020), 2020.

[8] Laihonen, H., A. Jääskeläinen, A. Lönnqvist, and J. Ruostela, "Measuring the productivity impacts of new ways of working", Journal of Facilities Management, 10(2), 2012, pp. 102-113.

[9] Davenport, T.H., "Rethinking knowledge work: A strategic approach", McKinsey Quarterly, 1(11), 2011, pp. 8899.

[10] Nicholson, D.B., J.A. Nicholson, D.V. Parboteeah, and J.S. Valacich, "Knowledge Worker Productivity", in Organizational and End-User Interactions, S. Clarke and A. Dwivedi, Editors. 2011. IGI Global.

[11] Wood, R.E., "Task complexity: Definition of the construct", Organizational Behavior and Human Decision Processes, 37(1), 1986, pp. 60-82.

[12] Aanestad, M., M. Mähring, C. Østerlund, K. Riemer, and U. Schultze, "Living with Monsters?", in Living with Monsters? Social Implications of Algorithmic Phenomena, Hybrid Agency, and the Performativity of Technology, U. Schultze, M. Aanestad, M. Mähring, C. Østerlund, and K. Riemer, Editors. 2018. Springer International Publishing: Cham.

[13] Plesner, U. and E. Husted, Digital organizing: Revisiting themes in organization studies, Red Globe Press, 2020.

[14] Kearns, G.S. and A.L. Lederer, "The impact of industry contextual factors on IT focus and the use of IT for competitive advantage", Information \& Management, 41(7), 2004, pp. 899-919.

[15] Eisenhardt, K.M. and D. Sull, "Strategy as Simple Rules", Harvard Business Review, 2001.

[16] Grant, R.M., Contemporary Strategy Analysis, 7th edn., Wiley, West Sussex, UK, 2010.

[17] Drucker, P.F., "Knowledge-Worker Productivity", California Management Review, 41(2), 1999, pp. 79-94.

[18] Keen, P. and R. Williams, "Value Architectures For Digital Business: Beyond The Business Model", MIS Quarterly, 37(2), 2013, pp. 643-647.

[19] Wunderlich, N. and R. Beck, "You'll Be Surprised Digital Business Strategy as Driver of Organizational Innovativeness", Proceedings of the 51st Hawaii International Conference on System Sciences (HICSS 2018); Big Island, Hawaii, USA, 2018, pp. 4035-4044.

[20] Jacobides, M.G., C. Cennamo, and A. Gawer, "Towards a theory of ecosystems", Strategic Management Journal, 39(8), 2018, pp. 2255-2276.

[21] Bharadwaj, A.S., "A Resource-Based Perspective on Information Technology Capability and Firm Performance: An Empirical Investigation", MIS Quarterly, 24(1), 2000, pp. 169-196.

[22] Sabherwal, R. and P. Tsoumpas, "The development of strategic information systems: some case studies and research proposals", European Journal of Information Systems, 2(4), 1993, pp. 240-259.

[23] Ravichandran, T., "Exploring the relationships between IT competence, innovation capacity and organizational agility", The Journal of Strategic Information Systems, 27(1), 2018, pp. 22-42. 
[24] Peppard, J., "Rethinking the concept of the IS organization", Information Systems Journal, 28(1), 2018, pp. 76103.

[25] Tiwana, A. and S.K. Kim, "Discriminating IT Governance", Information Systems Research, 26(4), 2015, pp. 656674.

[26] Lu, Y. and K. Ramamurthy, "Understanding the Link Between Information Technology Capability and Organizational Agility: An Empirical Examination", MIS Quarterly, 35(4), 2011, pp. 931-954.

[27] Taylor, J. and J. Vithayathil, "Who delivers the bigger bang for the buck: CMO or CIO?", The Journal of Strategic Information Systems, 27(3), 2018, pp. 207-220.

[28] McAfee, A. and E. Brynjolfsson, "Big Data: The Management Revolution", Harvard Business Review, 90(10), 2012, pp. 60-68.

[29] Goodhue, D.L. and R.L. Thompson, "Task-Technology Fit and Individual Performance", Management Information Systems Quarterly, 19(2), 1995, pp. 213-236.

[30] Campbell, D.J., "Task Complexity: A Review and Analysis", Academy of Management Review, 13(1), 1988, pp. 40-52.

[31] Liu, P. and Z. Li, "Task complexity: A review and conceptualization framework", International Journal of Industrial Ergonomics, 42(6), 2012, pp. 553-568.

[32] Ghasemaghaei, M., S. Ebrahimi, and K. Hassanein, "Data analytics competency for improving firm decision making performance", The Journal of Strategic Information Systems, 27(1), 2018, pp. 101-113.

[33] Nonaka, I., "A Dynamic Theory of Organizational Knowledge Creation", Organization Science, 5(1), 1994, pp. 14-37.

[34] Alavi, M. and D.E. Leidner, "Review: Knowledge Management and Knowledge Management Systems: Conceptual Foundations and Research Issues", MIS Quarterly, 25(1), 2001, pp. 107-136.

[35] Brynjolfsson, E. and A. Saunders, Wired for innovation: How information technology is reshaping the economy, MIT Press, Cambridge Mass., 2010.

[36] Peppard, J. and J. Ward, "Beyond strategic information systems: Towards an IS capability", The Journal of Strategic Information Systems, 13(2), 2004, pp. 167-194.

[37] Rungtusanatham, M., J.W. Miller, and K.K. Boyer, "Theorizing, testing, and concluding for mediation in SCM research: Tutorial and procedural recommendations", Journal of Operations Management, 32(3), 2014, pp. 99-113.

[38] Wunderlich, N., "Exterminate? - Who Influences IT Alignment and Digital Business Strategy", Proceedings of the 26th European Conference on Information Systems (ECIS 2018); Portsmouth, UK, 2018.

[39] Ravichandran, T. and C. Lertwongsatien, "Effect of Information Systems Resources and Capabilities on Firm Performance: A Resource-Based Perspective", Journal of Management Information Systems, 21(4), 2005, pp. 237-276.

[40] Zimmer, J.C., R.M. Henry, and B.S. Butler, "Determinants of the Use of Relational and Nonrelational Information Sources", Journal of Management Information Systems, 24(3), 2007, pp. 297-331.
[41] Spector, P.E., "Do Not Cross Me: Optimizing the Use of Cross-Sectional Designs", Journal of Business and Psychology, 34(2), 2019, pp. 125-137.

[42] OECD, OECD Science, Technology and Industry Scoreboard 2013, Organization for Economic Cooperation \& Development, Paris, France, Washington, USA, 2013.

[43] Warner, K.S. and M. Wäger, "Building dynamic capabilities for digital transformation: An ongoing process of strategic renewal", Long Range Planning, 52(3), 2019, pp. 326-349.

[44] Ringle, C.M., S. Wende, and J.-M. Becker, "SmartPLS 3", SmartPLS, Boenningstedt, Germany, 2016.

[45] Cassel, C., P. Hackl, and A.H. Westlund, "Robustness of partial least-squares method for estimating latent variable quality structures", Journal of Applied Statistics, 26(4), 1999, pp. 435-446.

[46] Hair, J.F., G.T.M. Hult, C.M. Ringle, and M. Sarstedt, A primer on partial least squares structural equation modeling (PLS-SEM), SAGE, Los Angeles, 2017.

[47] Chin, W.W., The Partial Least Square Approach to Structural Equation Modeling, Lawrence Erlbaum Associates, Mahwah, New Jersey, USA, 1998.

[48] Podsakoff, P.M., S.B. MacKenzie, J.-Y. Lee, and N.P. Podsakoff, "Common method biases in behavioral research: A critical review of the literature and recommended remedies", Journal of Applied Psychology, 88(5), 2003, pp. 879903.

[49] Fornell, C. and D.F. Larcker, "Evaluating Structural Equation Models with Unobservable Variables and Measurement Error", Journal of Marketing Research, 18(1), 1981, pp. 39-50.

[50] Paternoster, R., R. Brame, P. Mazerolle, and A. Piquero, "Using The Correct Statistical Test For The Equality Of Regression Coefficients", Criminology, 36(4), 1998, pp. 859866.

[51] Preacher, K.J. and A.F. Hayes, "Asymptotic and resampling strategies for assessing and comparing indirect effects in multiple mediator models", Behavior Research Methods, 40(3), 2008, pp. 879-891.

[52] Wunderlich, N. and R. Beck, "We've Got the Power The Relevance of IT Leadership and Organizational IT Capabilities in the Fully Digitized Business Era", Proceedings of the 25th European Conference on Information Systems (ECIS 2017); Guimaraes, Portugal, 2017.

[53] Alt, R., J.M. Leimeister, T. Priemuth, S. Sachse, N. Urbach, and N. Wunderlich, "Software-Defined Business", Business \& Information Systems Engineering (BISE), 62(6), 2020, pp. 609-621.

[54] Wunderlich, N. and R. Beck, "25 Years of CIO and IT Leadership - Revisiting Managerial Roles in Information Systems Research", Proceedings of the 21st Pacific Asia Conference on Information Systems (PACIS 2017); Langkawi, Malaysia, 2017. 